references to any material that could possibly be called celluloid. On the contrary, he recommends the following mixture as a suitable solvent for soluble guncotton or Xyloidine:

250 parts by weight of alcohol.

150 parts by weight of ether.

10 parts by weight of nitrobenzole.

33 parts by weight camphor or camphor oil.

250 parts by weight hydrocarbons, from coal, shale or other bituminous substances boiling between 220 and $400^{\circ} \mathrm{F}$.

Or he says the following solvent may be employed:

400 parts alcohol.

200 parts of hydrocarbons, before referred to, and 33 parts of camphor or of camphor oil.

Now this patent was taken out nearly five years after Hyatt's celluloid patent and although Spill in this patent suggests adding a small quantity of camphor to large quantities of other solvents, volatile and nonvolatile, he always mentions it as camphor or camphor oil, regarding them as equivalents. They certainly are equivalents for Spill's purposes to produce liquid solutions of pyroxyline, but camphor oil is not equivalent to camphor in Hyatt's process for making celluloid and it would be absolutely impossible to make celluloid by any process suggested in any one of these patents of Spill or Parks, or any other inventor prior to Hyatt, and this is what the federal judges decided when the matter was tried out in court.

Mr. Hyatt's activities were not limited to celluloid. Among his other inventions also of great importance, we find a sugar cane mill, very superior to any mill previously used, in its efficiency both in increasing the percentage of juice extracted from the cane and in greatly diminishing the time necessary to extract it, and in giving a higher value to the refuse bagasse as fuel.

In the early 80's, Mr. Hyatt and his brother Isaiah took up the subject of water filtration and started a company called the Hyatt Pure Water Company. Isaiah Hyatt invented and patented a very important feature of the filtration process, February I9, I884, Patent 293,740. It marks the beginning of a new era in water purification. Coagulants had been previously used to purify water, but the difficulty was that the water was held in large tanks or cisterns. The coagulant was added to it, the whole was thoroughly agitated and then it was necessary to allow it to stand 12 to 24 hours for the coagulum to settle to the bottom. The Hyatts conceived the idea of employing a coagulant which could be added to the water while on its way to the filter, so that no large settling tanks or basins are required and no time is lost. The claim of this patent is as follows:

"The method herein described of arresting and removing the impurities from water during an uninterrupted passage of the same from a supply pipe into a filtering apparatus, thence through a filter bed contained therein and out through a delivery pipe leading therefrom, which method consists in introducing into the water simultaneously with its passage to or into the filter a substance which will sufficiently coagulate or separate the impurities to facilitate their arrest and removal by the filter bed, thus obviating the necessity of employing settling basins.

I was connected with a litigation which followed the issue of this patent, and studied the process and apparatus at Somerville, N. J., Niagara Falls and Elmira. The process was unusually successful. At Somerville the river water exhibited a milky opalescence caused by such fine particles of clay that no filter would clarify it. By a proper attachment of an alum box to the feed pipe to the filter, a minute quantity of alum was added to the stream of water on its way to the filter, less than one grain to the gallon, and in the few seconds that elapsed before the water reached the filter bed of the ingeniously constructed Hyatt filter, coagulation had taken place and the coagulum including the alumina of the alum and the clay, bacteria and other suspended impurities of the water had been converted into such flocks as made it possible for the bed of sand in the filter to arrest it completely. These Hyatt filters are so constructed, whether they are on a large scale or small scale, that they can be washed completely at any convenient moment by simply reversing the current through the filter. This churns up the sand and separates from it the accumulated coagulum.

Nearly all the paper mills and woolen mills in the country were and still are supplied with these filters, as are also more than roo cities and towns.

The validity of this patent was established through lawsuits which were brought against the cities of Elmira and Niagara Falls. These cities attempted to evade the Hyatt patents by constructing a chamber underneath the filter through which the water passed on its way to the filter, but we found by examination that while a portion of the coagulum accumulated in the chamber, one-third of it passed on and was separated by the filter. Judgments in favor of the Hyatt patent were given by the Circuit Court of the United States, Judge Shipman presiding, in 1894; by Circuit of Appeals, Judge Wise presiding, in 1895 ; again by Judge Coxe in 1896 ; and again by Judges Wallace, Lacomb and Shipman in 1897 .

In 189I-2 Mr. Hyatt took up the subject of antifriction roller bearings with great success.

I have really occupied far more time than I should have done, but I felt it a duty to take advantage of this opportunity to present the facts with regard to Mr. Hyatt's priority of invention in connection with the celluloid and water purification, which I was in a position to do owing to my experience and knowledge gained in the litigations which arose in both cases.

I think that the facts to which I have called your attention, although very briefly expressed, will satisfy you of the great achievements of Mr. Hyatt and will fully justify your committee in placing Mr. Hyatt beside Sir William Henry Perkin and the six American chemists who have already received the Perkin medal.

To Mr. HyatT:

It gives me great pleasure, as the representative of the Society of Chemical Industry, and the affiliated chemical and electrochemical societies, to place in your hands, Mr. Hyatt, this beautiful token of the appreciation and affection of your fellow chemists.

\section{ADDRESS OF ACCEPTANCE}

By JoHn WeSLEY HyatT

Mr. Chairman, Ladies and Gentiemen:

I have never looked forward to any such honors as you have bestowed upon me, and I do not know how fittingly to express my gratitude. You have overlooked my lack of early training in the sciences with which you are all familiar, and look only to results which have been obtained mainly by persistent, and many times mistaken, experiments. Some successful experiments I might never have made if I had been familiar with the danger theories of some learned men.

\section{CELLULOID}

From my earliest experiments in nitrocellulose, incited by accidentally finding a dried bit of collodion the size and thickness of my thumb nail, and by my very earnest efforts to find a substitute for ivory billiard balls, it was apparent that a semiliquid solution of nitrocellulose, three-fourths of the bulk of which was a volatile liquid and the final solid from which was less than one-fourth the mass of the original mixture, was far from being adapted to the manufacture of solid articles, and that I must initially produce a solid solution by mechanical means. The only useful solvent known to me at that time was a mixture of alcohol and sulfuric ether; with the old formula (about equal parts of ether and alcohol) I mixed in a closed mill a thick paste of soluble cotton, made by the old firm of Charles Cooper $\&$ Co. After mixing, the cover of the mill was removed and the mass evaporated down to a thick dough, which was then forced 
accurately around the ball (made of another substance), and allowed to dry. This I found resulted in a rather brittle coating, owing, as I found, to the unequal evaporation, leaving only the a cohol, a poor solvent by itself, at the final shrinkage. This was remedied by using only the least amount of alcohol (five parts ether to one alcohol) necessary as a solvent. Even this coating shrunk to less than half of its original thickness and required to be dried immersed in water under several hundred pounds' pressure per square inch to insure its solidity and freedom from bubbles. It became necessary to strain the mass by forcing it through a very fine sieve to exclude the unnitrated fibers. All these difficulties stood in the way of success, except in high-priced articles like billiard balls. Other seriously objectionable features became apparent. In order to secure strength and beauty, only coloring pigments were added, and in the least quantity; consequently a lighted cigar applied would at once result in a serious flame, and occasionally the violent contact of the balls would produce a mild explosion like a percussion guncap. We had a letter from a billiard saloon proprietor in Colorado, mentioning this fact and saying he did not care so much about it, but that instantly every man in the room pulled a gun.

I next had a small beating engine made, to pulp the nitrocellulose. In one experiment I placed a small quantity of this dried pulp in a strong cylinder and forced quickly a minimum quantity of liquid solvent into it with high pressure. The result was a solid substance, as hard as sole-leather, which soon dried, leaving a fine, hard disc about three-fourths of an inch in diameter and one-half an inch thick. While no explosion ever resulted from this, there was real danger to be feared, and the matter was dropped.

My brother, I. S. Hyatt, joined with me at that time, and finding it stated in some patents to which $I$ was referred, that a little camphor added to the liquid solvent was beneficial, we conceived the idea that it might be possible to mechanically mix so vents with the pulp and coloring matter while wet, then absorb the moisture by blotting papers under pressure, and finally submit the mass to heat and pressure.

To our surprise, we noticed a slightly solvent action of the precipitated and washed camphor upon the pulp, even before the heat and pressure, and without other solvent we succeeded in producing a transparent slab one-fourth of an inch thick, fine, and as hard as a piece of wood. My brother took some samples to the American Hard Rubber Company, with the view of interesting them. They employed the late Professor Charles A. Seeley, who had made collodion for the government during the Civil War, to investigate the matter. He came to our place in Albany, $X$. Y., and we conducted the whole process for his inspection, very successfully. He remarked that he had come prepared to detect some chicanery, but could see no deception, and expressed himself as satisfied. He kindly advised us that if, accidentally or otherwise, we were to apply a little too high temperature, the quantity we were dealing with would inevitably destroy us with the building and adjacent property. While we did not accept this as true, it was disturbing. The following day between $I 2$ and $I$, when all were out, I rigged up a four-inch plank used as a vice-bench, braced it between the floor and ceiling, between the hydraulic press and the hand pump, intending it to shield me from possible harm. I then prepared the mould, heating it to about $500^{\circ}$ Fahrenheit, knowing it would certainly ignite the nitrocellulose and camphor, and thinking I would abide by the result. The gases hissed sharply out through the joints of the mould, filling the room with the pungent smoke. The mould, press, building and contents were there, including myself, very glad that I did not know as much as the Professor.

The next step was to make a small stuffing machine, consisting of a cylinder, four-inch bore, about a foot long, termi- nating in a tube three-fourths of an inch bore, ten inches long, immersed in an open oil-jacket, with a gas burner and thermometer. A capnut with one and one-fourth inch screw forced a plunger upon the cakes of incipient celluloid, which were heated at the outlet end of the cylinder passing through the heated tube into moulds, and also through nozzles forming rods, tubes, etc.

We found it advisable to lower the melting point of the camphor by adding a small quantity of alcohol or other solvent of camphor. A much larger hydraulic stuffing machine was then made. Dental plate blanks were the principal part of our early business.

My brother interested some New York capitalists-principally composed of General Marshall Lefferts, Joseph Larocque and Tracey R. Edson-and we removed to Newark, N. J., in the winter of $1872-73$. We had nearly all the appliances and machinery to design and build, which progressed with some halts and mistakes for two or three years, when a fire occurred in our four-story and basement building, utterly destroying all our stock and machinery, pushing out the whole front of the building (which was very weak), and severely injuring several of our men, who all finally recovered, although one-Mr. Charles S. Lockwood-was in great danger for a long time. We then started our present works, acquiring knowledge and experience; my brother started a separate factory for making brushes, mirrors and combs. Early in 1878 , my brother went to Paris and started the French Celluloid Company

Before we left Albany we began the use of tissue paper in place of carded cotton or bleached flax, which finally resulted in getting tissue paper of definite thickness and materials, and breaking it up into small, separate pieces by a machine I constructed, drying these separate pieces in a loose mass and nitrating them instead of the carded cotton.

In 1876 , I was allowed to employ a chemist for determining our acids and to systematize our nitration, instead of merely using hydrometers and thermometers, and Mr. Frank Vanderpoel was selected by me. So far as I know, the analyses of mixed spent acids was not reduced to practical work. Professor Seeley proposed that we separate the nitric and sulfuric acids by distillation, and then bring these to the proper strength before mixing, which was not adopted. Vanderpoel first removed the gelatinous flock by adding finely powdered natural barium sulfate and allowing the barium and flock to subside, which was a great success. I had previously tried filtration, which was impractical. After much labor Vanderpoel perfected a quick and accurate method of determination of the spent acids, and then added the required fresh acids. An elaborate and extensive battery of tanks was constructed, the acids being moved through copper pipes, where required, by means of air pressure. The tanks for mixing the comminuted tissue paper with the prepared acids were arranged on a turntable supporting a dozen or more tanks, each holding hundreds of pounds. A rotating stirrer was arranged to stir in the requisite amount of paper in one tank, the turntable being revolved to the next tank, and so on. At a distance embracing about half a dozen tanks from the stirrer was located a centrifugal machine, which separated out most of the acids. The nitrated paper was then thrown into a washing device, and the partly washed paper then fell into large tanks of fresh water and was thoroughly washed. A very considerable number of tons of paper per day were and are treated in this way.

The next procedure was to grind this nitrated paper in a beating engine. The water was then mainly removed by a centrifugal machine. The mixture of pigments, camphor and nitrocellulose was then made, according to the results required, and ground together in a mill, then pressed into slabs or cakes, still further deprived of moisture by great pressure, and finally deprived entirely of moisture by blotting papers, repeatedly 
changed. These cakes were then broken up and alcohol or other desired solvents added and allowed to soak in. The partly dissolved mass was then masticated in heated rolls, turned out into necessarily rough sheets, cut into strips and rolled up into cylinders, ready for the stuffing machine.

The great need was for Celluloid in solid perfect sheets, and this neither the rolls nor the stuffing machines could possibly do, with all our experience. I constructed a special nozzle for the stuffing machine, to form a slab about one and one-half inches thick, seven inches wide and several feet long, which was pressed between steam plates, one of them with under-cut grooves to hold the slab. A machine was made with shaving knife and reciprocating bed, and by it the slab was shaved into sheets of the desired thickness. These slabs were necessarily imperfect, and were too small. After showing this result to the other directors, I proposed building a hydraulic pressure steam-heated mould, to make a slab or block about two feet by five, and three inches thick, in which to weld and press a pile of rough sheets from the masticating rolls.

General Lefferts, our much beloved president, had suddenly died a year or more before. To those who knew the least about Celluloid my suggestion looked pretty good, but to others came a great fear of possible danger and failure to weld up such a mass. At last they gave me authority to build the apparatus, limiting me to less than half its cost if fairly estimated. With this authority, which consisted more of the privilege of trying such an apparatus than in providing for its cost, I ordered the machine, agreeing to pay the machinist all above the appropriation if it failed to work. The machine was built and most carefully tried in the presence of only the new president, who knew little about celluloid, and Mr. Stevens and Mr. Lockwood from among the employees. The mould was cooled and opened, and nice sheets were at once made, considering that only scrap material was used, though less than half the block was welded. This meant reheating, which was at once done, and the whole was known to be a success.

I dwell upon this because of its vast importance to us. It multiplied the value of celluloid many times, making a much stronger and finer material than was produced by the former means.

About this time we were enjoined from bleaching the iron out of the pulp, caused by the iron-beating knives, and it was up to me to remedy the serious difficulty. A large revolving drum of copper, through the axis of which was a shaft with beating arms rotating at a very high speed, in which the mixture of nitrated paper, camphor and pigmets was placed, and the whole beaten to a pulp without the discoloration of the iron and water, and without the loss in washing and bleaching the fine pulp from the beating engine.

In order to clearly differentiate my work in celluloid from that of others in the nitrocellulose industry, I will summarize as briefly as I can.

First: The idea of combining with the nitrocellulose only the exact or approximate amount of solvent required for a solid solution. This required a nearly perfect mechanical mixture before very much solvent action could take place.

Second: Completing the solution by means of heat and pressure.

Third: Eliminating the practically unnitrated fibers by pulping.

Fourth: Employing tissue paper in place of carded fiber.

Fifth: Avoiding the terrible danger of drying out the moisture by exposure in a drying room.

Many years ago I patented the process of first pressing out all the water possible and displacing the remainder by forcing alcohol through under pressure. This, I understand, is now used by other nitrocellulose workers, but we prefer the method herein described.

Sixth: The stuffing machine process.

Seventh: The sheeting process, most essential.

\section{ACKNOWLEDGMENTS}

Mr. Stevens has been with me ever since he was fourteen years old, has invented solvents and many other things of great importance in the art, and stands at the head of nitrocellulose workers at the present time.

Mr. Harrison, in his department, has invented the method of imitating the grain of ivory, of smoked pearl, of onyx, as well as many other beautiful colors and effects. He has been with us nearly forty years

Others are entitled to much credit, but it is impossible to name them here.

\section{SUGAR-CANE MILL}

In the old method of milling sugar cane the cane is passed between rolls which are generally 34 inches in diameter and 84 inches long. These rolls are grooved and roughened so as to draw all the cane in between them that is possible. Owing to the comparatively obtuse angle formed by the contact of two rolls, the quantity of cane is limited and they are very nearly together at the passage of the cane through the last pair of rolls. The last, say I 5 per cent, of the juice is forced out through five or six inches of highly compressed fiber in the opposite direction from which the cane is moving, so that in practice a considerable portion of the juice is carried through the rolls. For this reason it is repeatedly passed through rolls, at each passage removing a small proportion more of the juice. It is found profitable in most cases to add water to the bagasse between each set of rolls so as to dilute the juice that necessarily remains in the bagasse. In order to get the desired quantity of work from the mill, the rolls are of great length, from seven to seven and one-half feet. There are generally from 30 to 40 tons of pressure for each foot of face of the rolls. It is not practicable to get any greater pressure than this. I employ four or five times as much pressure per lineal foot.

With my apparatus and method the angle formed between the chain and the upper roll is far more acute and the cane is forced through rolls so that five times more cane goes through the rolls of a given face than is possible with the old mills. If this chain belt were impervious to the juice little or nothing would be gained by this method, but inasmuch as the chain forms a massive screen through which the juice may readily escape from the underside, the juice has only to pass downward through the mass perhaps one and one-quarter inches at the most to escape, instead of five or six inches in the opposite direction to the progress of the cane, as in the old mill. It does not take any more powerful apparatus to press the cane fiber when it is one inch thick than it does to press fiber that is oneeighth of that thickness, and as I get quite as much cane through my rolls with I2-inch face as will pass through the old rolls of 84-inch face I can readily afford to put several times as much pressure upon each foot of face as is practicable with the old mills. I employ upward of 150 tons on rolls with 12 -inch face.

For the same amount of cane passing six times through the present rolls my mill will not require more than one-third as much power and instead of getting with the best milling a bagasse with 50 per cent of moisture and 50 per cent of fiber, I can easily produce a bagasse which has 60 per cent of fiber and 40 per cent of moisture. This bagasse is so dry that a quantity of it, either a handful or a bushel, placed upon the ground can be lighted with a match and will burn like carpenter's shavings. My mill is about one-eighth the weight of the present mills with the same capacity, and as the machine work is of the same character the machine will not cost one-quarter as much as the present mills.

In Cuba, 7 I per cent of extraction without dilution is as good as can be obtained. With my mill, without dilution, $I$ can easily get 78 per cent extraction. With Louisiana cane, which has less fiber, I can easily get 84 per cent extraction without dilution. Of course, if the bagasse is passed through a second mill with 12 per cent dilution, I can get 88 per cent extraction. 
The joints of my sprocket chain belt are self-cleaning and cannot clog; as shown in practice, each revolution of the chain rubs the screen surface together several times. All the links of the chain are alike, and are of drop-forged steel. The concave edges of these links absolutely fit the under roll. The smaller pressing roll is provided with annular grooves coinciding with the longitudinal joints of the chain so that even the last small percentage of juice has a perfectly free outlet.

There is no danger from irregular feeding, as the mass of bagasse between the rolls is about one and one-quarter inches thick, and no loose or open space can possibly exist. The springs yield or follow up, according to the feed. No crusher or shredder is necessary or desirable.

The speed of the surfaces of the rolls and chains is designed to be 3 o feet per minute, although I did practically as good work on my previous machine at 40 feet per minute, and it will probably be proved that this machine can do equally as good work at 40 feet per minute, but to be safe, I have calculated it for 30 feet per minute. The ordinary cane mills are run at anywhere from 16 to 25 feet per minute, according to the choice of the owner or engineer.

The increased value of the bagasse as fuel, and the avoidance of any peculiar kind of bagasse burner with forced draft, etc., are quite important items. Furthermore, as was shown by my machine at Adeline, Iouisiana, the purity of the juice is considerably improved, as the cane is not ground up as in the ordinary mills, but merely flattened by the great pressure.

I have taken out 238 patents (a few of them being joint inventions with others), and several new industries have resulted. The one of next importance to celluloid is the Hyatt Roller Bearing. I have received considerable liquid money, most of it having been of a volatile and inflammable nature. Age ought to bring wisdom.

\section{PERSONAL REMINISCENCES}

BY FRANK VANDERPOEL

\section{Mr. Chairman, Ladies and Gentlemen:}

It is a great pleasure, I can assure you, to be present this evening, at a time when, in company with the preceptor whom all the boys of Columbia love, we are to do honor to my friend of later years, when what was taught me by the former became the equipment for my work with the latter. Every young fellow who had the good fortune to study chemistry under Dr. Chandler will bear me witness that the days thus passed were very enjoyable indeed: the memory of them will last long in our minds, no matter where, or in what circumstances we may find ourselves. When the request came to me from our worthy chairman to say something this evening at the presentation of this medal, I could not help feeling that there were other members of the societies which we represent who could do the subject more justice than I. There is no other, however, who is more gratified at the awarding of the medal. The only reason that I can think of for the selection of the speaker is that for a long term of years he has been the intimate friend and associate of the recipient of the medal.

Let me say, further, that when I was asked to take part in the exercises, it seemed almost as if $I$ had been requested to as sist at the obsequies of an old friend who had departed this life; for, of course, no one could be expected to say anything at such a time as this except in praise; anything else, even if it were possible, which it is not, would seem very ungracious indeed, and so, the recipient of the medal must listen, perforce, like Tom Sawyer and Huckleberry Finn, in Mark Twain's humorous story, when they came to their own funeral, to words of eulogy and praise of which he has never dreamed. However, let us dismiss from our minds the thought that our friend is a departed one. $\mathrm{He}$ is very much alive: we haven't come here to bury him, and what we are about to say we are going to tell him to his face, and not apologize for it either. If you will permit personalities, Mr. Chairman, without which I don't believe I could get through with my talk, I should like to say that it was about three years after leaving Columbia that I had the good fortune to meet our guest of the evening. It happened at a time when I was desirous of locating myself where I could do laboratory work on a somewhat larger and more efficient scale than I had been able to do before. Without going into details, let me say that I met Mr. Hyatt, had a chat with him, found that he had discovered the need of an analyst at the works of The Celluloid Manufacturing Company, as it was then called, applied for such a position, and secured it through his kindness and influence. From that time until the present, and this means a long series of years, we have been friends, and our friendship has stood the test of sun and rain, of bright and cloudy days, of the ups and downs which every manufacturing business must have, and I think that we are as strong friends as ever, at this moment. In fact, I don't believe that there is anyone present who is more pleased than $\mathbf{I}$ am that the Perkin Medal has been awarded to him-unless it be Mr. Hyatt himself.

To refer to the early days of the celluloid business in Newark, where the factory was located, I should like to say that there seemed to be a good deal of prejudice against it in that city. On account of an unfortunate fire which took place there shortly after the company began operations, the people of Newark did not, as a rule, take kindly to a material which was reported as being made of guncotton and camphor. Of course, such a statement would never lose in transmission, and the people would look askance at any article of commerce which contained, as an ingredient, this high explosive. I remember hearing a story told of a man who happened to touch, with a lighted match, one of a pair of cuffs made of celluloid when, to his amazement, there was a terrible explosion, and he barely escaped with his life. Well, this and other stories of a like nature produced a strong feeling against the manufacture of this new substance, to say nothing of its use by the public, and, of course, some one had to bear the brunt of it. Naturally, the inventors (The Hyatt Brothers) and those most intimately associated with them in the business, had to carry the burden; and it wasn't a very light one, either. But our friend had the enthusiasm of the inventor, an enthusiasm which he imparted to those who were associated with him, and without which success would have been long delayed, if not impossible. I suppose that, in the minds of some, even at the present day, the idea exists that the principal ingredient in the material referred to is true guncotton, the highly-nitrated compound of cellulose. This is because the public, as a rule, is not given to distinguishing between the compositions of different chemical compounds. If, in order to make true guncotton, you treat cotton fiber with a bath composed of a mixture of strong sulfuric and nitric acids, why, it stands to reason--so some of these people think-that cotton fiber treated with a bath of these same acids, no matter what their percentage composition may be, will be converted into the explosive compound. You know that this is not the case, but the general public does not, or did not, some thirty years ago. If you will pardon the digression, I should like to say that, shortly after I became associated with the Celluloid Company samples were made of these two varieties of nitrocellulose, using raw cotton fiber in each case, and their solubility tested in a strong solvent, and thus compared. Any nitrocellulose which would not dissolve in this solvent would be utterly worthless as a basis for the manufacture of our product.

Upon making the test, the fibers of the lower nitrated compound disappeared in the solution upon the instant that they touched the solvent. This was the variety of nitrocellulose 